\title{
Active and non-active stations as an adaptive method for Objective Structured and Clinical Examination during the COVID-19 pandemic
}

\author{
Ida Musfiroh, Holis Abdul Holik, Raden Bayu Indradi, Sriwidodo \\ Faculty of Pharmacy, Universitas Padjadjaran, Indonesia
}

\author{
Keywords \\ Active and Non-active stations \\ Innovation \\ Lab skill \\ OSCE \\ Pharmacist

\section{Correspondence} \\ Ida Musfiroh \\ Pharmacist Study Programme \\ Department of Pharmaceutical \\ Analysis and Medicinal Chemistry \\ Faculty of Pharmacy \\ Universitas Padjadjaran \\ Indonesia \\ ida.musfiroh@unpad.ac.id
}

\begin{abstract}
Objective: The COVID-19 pandemic caused by the SARS-CoV-2 infection is of global concern. In mid-March 2020 all learning activities in Indonesia were carried out online. The biggest challenge in measuring the competency of graduates during this pandemic time was to test skills online. The aim of this study was to develop adaptation of the online Objective Structured and Clinical Examinations (OSCE) model at the Apothecary programme, Universitas Padjadjaran, Indonesia. Methods : The OSCE online method is designed using two systems, namely active stations and non-active stations with competencies tested based on the OSCE blueprint, and with the application of virtual facilities such as Google meet, Google forms, etc. Results : The results showed that this method can be used for lab skills exams so that candidates and examiners can still take the exam comfortably without being disturbed. The methods can evaluate competence using the Global Rating and Actual Mark Score, and the examiner does not find it difficult to assess the competency being tested.
\end{abstract}

\section{Introduction}

The Coronavirus pandemic (COVID-19) had a great impact on the educational sector, particularly in the evaluation process of learning which requires the measurement of practical skills (Aristovnik et al., 2020). University and school closures forced educational institutions to transform all examinations to be conducted virtually (Wahab, 2020). In Indonesia, pharmaceutical education was one of those affected so that all the competency exams needed to be transformed (FIP, 2021).

The Indonesian pharmacist competency exam (UKAI) consists of two methods, namely a Computer-based test (CBT) and an Objective Structured Clinical Examination (OSCE) which are held by the Indonesian Pharmacy Higher Education Association (APTFI) in collaboration with the Indonesian Pharmacist Association (IAI) (Indonesian Pharmacist Competency Examination Committee, 2017). The UKAI-CBT method assesses the knowledge skills of the candidate, while the UKAI-OSCE evaluates the skills of the candidate in solving problems in pharmacy practice (Indonesian Pharmacist Competency Examination Committee, 2017; Susi et al., 2018).

APTFI, IAl and The National Pharmacy Committee (KFN) as the stakeholders of the pharmacists in Indonesia, have held the summative UKAI-CBT test since 2017 as an effort to improve and standardise the competency of the graduates in Indonesia (Ministry of Research, Technology and Higher Education, 2017). UKAI-CBT and UKAI-OSCE are both mandatory exit examinations for candidates. Currently, UKAI-CBT is held as summative exit exam, in which it is mandatory to attain a passing grade (Association of Indonesian Pharmacy Higher Education, 2020). The UKAI-OSCE is currently as a formative exam, which is mandatory, but does not impact graduation. The previous stage had been a pilot test, to validate the UKAIOSCE system at each institution nationally (Association of Indonesian Pharmacy Higher Education, 2020). Candidates 
who pass the UKAI-CBT and take the UKAI-OSCE exam will receive a Pharmacist Registration Permit (STRA) as a license to carry out pharmacy practice (Association of Indonesian Pharmacy Higher Education, 2020).

During the Covid-19 pandemic, all learning activities in Indonesia were carried out online (Abidah et al., 2020). However, measuring the competency of graduates must still be done by making innovations and adjusting the examination model. Currently, there is no established online OSCE exam standard, however, there are some published articles which can provide an overview on how online OSCE is applied in various countries and various educational fields with different methods (Meskel et al., 2015; Kakadia, Chen, \& Ohyama, 2020; Lawal et al., 2020). In this case study, the authors describe the experiences in carrying out the online OSCE exam for pharmacist students of Universitas Padjadjaran, Indonesia, during the Covid-19 pandemic.

\section{Methods}

\section{Educational Description}

The OSCE is to evaluate student clinical skill lab that has been implemented widely in pharmacy schools (Susi, \& Yosef, 2019). The skill lab refers to expertise in pharmaceutical practices such as motoric skill training (i.e. compounding of medication, operating appropriate equipment such as scales, instrument laboratory test and other measuring devices) and specific skills in the form of simulations. Due to the Covid-19 pandemic, APTFI issued a decision that the national formative UKAI-OSCE exam for July 2020 was abolished, and it was submitted to each study programme to conduct an integrated skills evaluation of prospective pharmacists as well as possible (Association of Indonesian Pharmacy Higher Education, 2020).

Therefore, to implement an integrated curriculum and skill evaluation for prospective graduates at the Faculty of Pharmacy Universitas Padjadjaran, Indonesia, while maintaining the safety of personnel, OSCE were conducted online using non-active stations (written tests using Google Classroom with supervisions via Google Meet) and active stations (active communication/counselling tests) systems remotely and were held over two days. At the non-active station, the students were divided into two large rooms along with the exam supervisors. Exam questions were displayed using screenshare features with a 15-minute time limit for each question and continuing to the next question automatically. Students then answered the question by filling the worksheet that had been provided just before the examination begin. During the examination, all students were supervised from the video camera of their own by the exam supervisors. At the end of the last question, students were required to upload their answer sheet into the Google Classroom within the allotted time. After that, exam supervisors checked the answer sheet and provide scores for each student based on the assessment rubric (see Appendix 1).

At the active station, the examiner can record and provide scores for communication-related competences directly, based on the assessment rubric. In this station, a standard patient was also prepared to help the communication run according to the problem scenario as in an actual OSCE. Technically, the use of different Google Meet links for each active station can anticipate stopping of the exam if something goes wrong, or if using a feature such as a breakout room and something happens with the meeting link, it might stop the examination completely. Furthermore, it can also reduce the possibility of participants entering the wrong room which can interfere with the running of the exam due to the many burdens for the host and co-host in dividing participants into their respective rooms. Therefore, it is necessary to have good technical preparation to ensure that the online exam is run well.

The OSCE online remained focused on OSCE learning outcomes based on the UKAI Blue Print based on the Indonesian Pharmacist Competency Standards (SKAI) (Center Management of Indonesian Pharmacist Association, 2016).

Based on these standards, several things were arranged to compile the online OSCE concept:

1.Determine the main learning outcomes based on the UKAI-OSCE Blueprint which can be achieved using the Online method

2.Determine the learning outcomes that can be achieved at the active station and non-active station

3.Set the tools to be used for non-active and active stations

4.Review the OSCE questions to suit the technical implementation online

5.Establish a scoring system with OSCE scoring rubrics

6.Compiling an OSCE team consisting of coordinator of OSCE centre, coordinator of exam questions and IT systems, coordinator of quarantine rooms, standard cast trainers, and examiners

7.Conduct trials prior to the exam day to assist adaptation for all OSCE elements and to find potential errors that could occur and how to mitigate them

8.Conduct implementation evaluation and performance evaluation 
Table I: Results from the Adaptive UKAI-OSCE competency exams implemented at Universitas Padjadjaran, Indonesia, during the COVID-19 pandemic.

\begin{tabular}{|c|c|c|c|c|c|}
\hline Number & Pharmacy Practice & $\begin{array}{l}\text { Online } \\
\text { Implementation }\end{array}$ & Case for Assessment & $\begin{array}{l}\text { Global Rating } \\
\text { Scores }\end{array}$ & $\begin{array}{l}\text { Actual Mark } \\
\text { Scores }\end{array}$ \\
\hline 1 & Research and Development & - & - & & \\
\hline 2 & Production & $\checkmark$ (Active) & $\begin{array}{l}\text { Uniformity test in in process control (IPC) of a batch } \\
\text { production of tablets and how to communicate the problem } \\
\text { with the supervisor }\end{array}$ & 1.95 & $72.3 \%$ \\
\hline 3 & $\begin{array}{l}\text { Quality Control/Quality Assurance (QC/ } \\
\text { QA) }\end{array}$ & $\checkmark($ Non-active $)$ & Determination of active content in herbal preparation & 1.98 & $70.2 \%$ \\
\hline 4 & Planning / procurement / acceptance & $\checkmark($ Non-active) & $\begin{array}{l}\text { Planning the procurement of drugs in the hospital using } \\
\text { Vital-Essential-Non Essential (VEN) method and filling the } \\
\text { order letter }\end{array}$ & 2.13 & $76.3 \%$ \\
\hline 5 & Storage / distribution / destruction & - & - & & \\
\hline 6 & $\begin{array}{l}\text { Drug services without a prescription } \\
\text { (Self-medication) }\end{array}$ & $\checkmark$ (Active) & Drug choice for the patient with cutaneous wart & 2.42 & $80.0 \%$ \\
\hline 7 & $\begin{array}{l}\text { Prescription screening/ analysis of drug- } \\
\text { related problems (DRP) }\end{array}$ & $\checkmark($ Non-active) & DRP analysis of a tuberculosis patient with liver problems & 1.79 & $67.4 \%$ \\
\hline 8 & $\begin{array}{l}\text { Compounding of sterile/non-sterile } \\
\text { products }\end{array}$ & $\checkmark($ Non-active) & Drug preparation from a prescription in pharmacy & 2.37 & $87.4 \%$ \\
\hline 9 & $\begin{array}{l}\text { Dispensing/ adverse drug reactions } \\
\text { monitoring }\end{array}$ & - & - & & \\
\hline
\end{tabular}

Table I shows the nine competencies included in UKAIOSCE blueprint (Indonesian Pharmacist Competency Examination Committee, 2017) of these nine competencies, three competency areas were excluded for the adaptive exam method; these were: R\&D, storage/distribution/ destruction, and dispensing/adverse drug reaction monitoring because they could be represented in other competencies being tested.

The adaptive OSCE online method in this case was covering almost $70.0 \%$ of UKAI-OSCE blueprint and still representing the three pharmacy practice areas, namely: Manufacturing of Pharmaceutical Dosage Form included in 1,2 and 3; Pharmacy Distribution included in 4 and 5; and Pharmacy Services included in 6,7, 8 and 9 by the UKAI-OSCE blueprint. The specific competencies tested still refer to SKAI (Center Management of Indonesian Pharmacist Association, 2016). The actual OSCE was conducted with nine working stations and one rest station. Each station represents all the nine competencies in the blueprint. Each student entered every station alternately in one round with a ten minute time limit per station. They were required to work as requested in each station instructions and the examiner was able to provide a score for the students without having direct interaction with the rubric scoring provided.

\section{Results}

The candidates and examiners could take the exam comfortably, without being distracted and the examiners did not have difficulty assessing the competencies being tested. The most important things in organising this online OSCE included legality (approved by the senate of the faculty), socialisation to candidates and examiners by conducting trial and error prior to the exam day, and preparation related to technical issues such as internet networks. Evaluation of the Competency Achievements tested in the adaptive method of OSCE was carried out using the borderline regression method system including the global mark and actual rating values. The results are shown in Table I, that the average of global rating scores and actual mark scores were 2.11 and 75.6, respectively. These results revealed that the average candidates received a passing score in the skills competency test through the adaptive method for the OSCE.

\section{Conclusion and Recommendations}

The Based on the results, this method can be used for Skill Lab exams as well as pharmaceutical practice exercises, with the following recommendations:

1.Active stations can be used to test effective communication skills and professional behaviour 
attitudes of candidates in all fields both manufacturing (production) and pharmacy service (self-medication).

2.Non-active stations can be used to test candidates' skills in data and information collection, problem determination, problem-solving in all areas, in manufacturing (QA/QC), pharmacy service (compounding, analysis of drug-related problems), and distribution, as well as recording and reporting.

3.In a situation that does not support face-to-face, online OSCE can support evaluating competencies in SKAI.

However, this method cannot evaluate the pharmaceutical laboratory practice of the candidates that requires laboratory instruments which becomes the limitation of this online exam method.

\section{References}

Abidah, A., Hidaayatullaah, H.N., Simamora, R.M., Fehabutar, D., \& Mutakinati, L. (2020). The Impact of Covid-19 to Indonesian Education and Its Relation to the Philosophy of "Merdeka Belajar". Studies in Philosophy of Science and Education. 1(1), 38-49

Aristovnik, A., Keržič, D., Ravšelj, D., Tomaževič, N., \& Umek, L. (2020) Impacts of the COVID-19 Pandemic on Life of Higher Education Students: A Global Perspective. Sustainability, 12(20), 8438. https://doi.org/ $10.3390 /$ su12208438

Association of Indonesian Pharmacy Higher Education. (2020). Circular Letter. 021/I/SE/APTFI/2018

Center Management of Indonesian Pharmacist Association. (2016). Indonesian Pharmacist Competency Standards

FIP (International Pharmaceutical Federation). (2021). FIP digital health in pharmacy education "Developing a digitally enabled pharmaceutical workforce". Andries Bickerweg The Hague. The Netherlands: 24-33

Indonesian Pharmacist Competency Examination Committee. (2017). Blueprint of Indonesian Pharmacist Competency Test-OSCE Method

Kakadia, R., Chen, E., \& Ohyama, H. (2020). Implementing an online OSCE during the COVID-19 pandemic. Journal of dental education, 10.1002/jdd. 12323. Advance online publication. https://doi.org/10.1002/jdd.12323

Lawal, B.K, Haruna, A., Kurfi, F.S., \& David, K.B. (2020). COVID-19 pandemic and pharmacy education in a developing country: A case study from Nigeria (online). Pharmacy Education. 20(2), 15-16. Available from: https://pharmacyeducation.fip.org/pharmacyeducation/article/view/1130

Meskel, P., Burke E., Kropmans T.J.B., Byrne E., Setyonugroho, W., \& Kennedy, K.M. (2015). Back to the future: An online OSCE Management Information System for nursing OSCEs (online). Nurse Education Today. 35(11), 1091-1096. https://doi.org/10.1016/j.nedt.2015.06.010

Ministry of Research, Technology and Higher Education. (2017). Implementation encouragement of summative UKAI. No 032/B/TU/2017
Susi, A.K., Nuvi, G., M.Rifqi, R., Hardika, A., \& Ika, P.S. (2018). Students' first experience with Objective Structured Clinical Examination in a pharmacy school in Indonesia. Journal of Applied Pharmaceutical Science. 8(9), 102-106

Susi, A.K., \& Yosef, W. (2019). Assessment of Pharmacy Students' Clinical Skills using Objective Structured Clinical Examination (OSCE): A Literature Review. Systematic Reviews in Pharmacy, 10(1), 55-60. https://doi.org/ 10.5530/srp.2019.1.9

Wahab, A. (2020). Online and Remote Learning in Higher Education Institutes: A Necessity in light of COVID-19 Pandemic, Higher Education Studies. 10(3), 16-25. https://doi.org/10.5539/hes.v10n3p16

\section{Appendix}

\section{Appendix 1}

\begin{tabular}{lll}
\hline $\begin{array}{l}\text { No Pharmacy } \\
\text { Practice }\end{array}$ & $\begin{array}{l}\text { Case of } \\
\text { assessment }\end{array}$ & Rubric \\
\hline 1 Production & Uniformity test 1.1 Able to determine the total amount of \\
in in-process tablet for uniformity testing based on \\
control (IPC) of Pharmacopeia \\
a batch produc- 1.2 Able to determine the amount of tablet for \\
tion of tablet the first step of uniformity testing based on \\
and how to co- Pharmacopeia \\
mmunicate the 1.3 Able to Interpret the results of uniformity \\
problem with testing data \\
the supervisor 1.4 Able to report about the results of \\
\end{tabular}

2 QC/OA Determination 2.1 Able to determine the chroma-tography of active con- system based on the Herbal Pharmacopeia tent in herbal 2.2 Able to calculate the active content by preparation Thin layer Chromatography-densitometry method and give the conclusion regarding the quality

2.3 Able to record the information needed in the document

2.4 Professional attitude and behaviour

3 Planning/ Planning the 3.1 Able to create the list of drugs needed Procurement procurement of 3.2 Able to fill the order letter based on the /Acceptance drugs in the classification of drugs

hospital using 3.3 Professional attitute and behaviour VEN method and filling the order letter

4 D $\quad r \quad u \quad g$ Drug choice for 4.1 Able to collect the information and assess services the patient with the patient's condition

without a cutaneous wart 4.2 Able to choose the correct drug at the pre-scription

4.3 Able to communicate with the patient regarding the drug information service 4.4 Professional attitude and behaviour

5 Prescription DRP analysis of 5.1 Able to find the drug-related problem from screening/ a TB patient the prescription with the patient condition analysis of with liver pro- 5.2 Able to find the solution from the problem drug-related blems regarding the drug regiment problems $\quad 5.3$ Professional attitude and behaviour

6 Compoundin Drug prepara- 6.1 Able to determine the amount of tablets $\mathrm{g}$ of Sterile/ tion from the needed for compounding non-sterile prescription in 6.2 Able to create the correct copy of products pharmacy prescription and label 6.3 Professional attitude and behaviour 